\title{
Improving Fire Protection of Pontoon Tanks or Floating Roof Tanks
}

\author{
Evgeniy Degaev $^{1 *}$, Dmitry Korolchenko ${ }^{1}$ \\ ${ }^{1}$ Moscow State University of Civil Engineering, Yaroslavskoye shosse 26, Moscow, 129337 Russian \\ Federation
}

\begin{abstract}
The paper presents research of new solutions to improve fire protection of pontoon tanks or floating roof tanks. Extinguishing efficiency of the subsurface supply system is boosted by a different configuration of the pontoon or floating roof, and also with a cooling system used for oil product evacuation. Efficiency of the proposed methods is more than doubled compared to the existing subsurface extinguishing method.
\end{abstract}

\section{Introduction}

Fire protection of tanks holding oil and its products relies on a combination system where the foam is served at the same time to the tank's base and to the annular space between the tank's roof and wall [1-4].

A serious disadvantage of all existing methods of fire extinguishing by serving foam to the tank's base, is its low efficiency when fighting fires inside tank pontoons or floating roofs. As the pontoon is partly flooded, the foam served from below tends to accumulate in the tank's one half but not to flow to the other half that is open on top. If a burst of the vapor-air mix blows the mounted foam generators off, the fire becomes practically unstoppable. Such cases have to use extra quantities of foaming agent [5-7].

Because estimated intensity of foam injection from the top can extinguish the fire only in the narrow gap between the floating roof and the wall, then if the pontoon or floating roof is partly flooded, it becomes impossible to extinguish fire over the entire exposed surface. Quantity of foam served to the tank's base is sufficient to extinguish fire on the entire area, but the tilted roof or pontoon blocks entry of foam into the partitioned area of the oil product surface. This creates a problem with using foam in the subsurface extinguishing system.

Extinguishing devices exist for oil and products burning inside tanks, where check valve are installed on pontoons and floating roofs near the tank walls, on the pontoon side some 1-3 $\mathrm{m}$ from the edge. Such check valves prevent propagation of foam supplied from above by foam generators installed in the tank's lower ranges. Such devices are designed to extinguish flame in the ring clearing, but foam jets deflect from the tank walls and fade within on the pontoon surface.

Special focus on fire extinguishing by supplying foam into the tank's base is explained by low reliability of foam supply systems with supply from above, from foam generators

\footnotetext{
*Corresponding author: degaev@inbox.ru
} 
installed on the upper edge of the tank wall, because when the vapor-air mix explodes inside the tank, it compromises integrity of suspended structures, and no foam can get into the tank [8-11].

The existing systems of fire extinguishing by supplying foam into the tank's base reliably protect tanks that have no pontoons and floating roof. Such tanks create no obstacles preventing foam from rising to the burning surface, and foam can extinguish foam in areas covered from above, for example by a collapsed permanent roof [12-14].

Another problem is organizing cooling for the tank's upper girth as oil products are evacuated from other tanks nearby that stand directly close to the tank in emergency. Water consumption rate to cool the tank's upper girth is very high, and it practically cannot be supplied for the entire duration of fire extinguishing $[15,16]$.

The purpose of this research is to improve fire protection of tanks with a pontoon or floating roof; this can be achieved by solving the following problems:

- reconfiguring the pontoon or floating roof to redistribute foam over the entire combustion area;

- designing a cooling system for the tank's upper girth for other tanks nearby that stand directly close to the tank in emergency until all oil products can be evacuated.

\section{Materials and Methods}

The proposed device is schematically illustrated in Fig. 1 and 2. We have tested devices with different diagrams and different number of wholes.

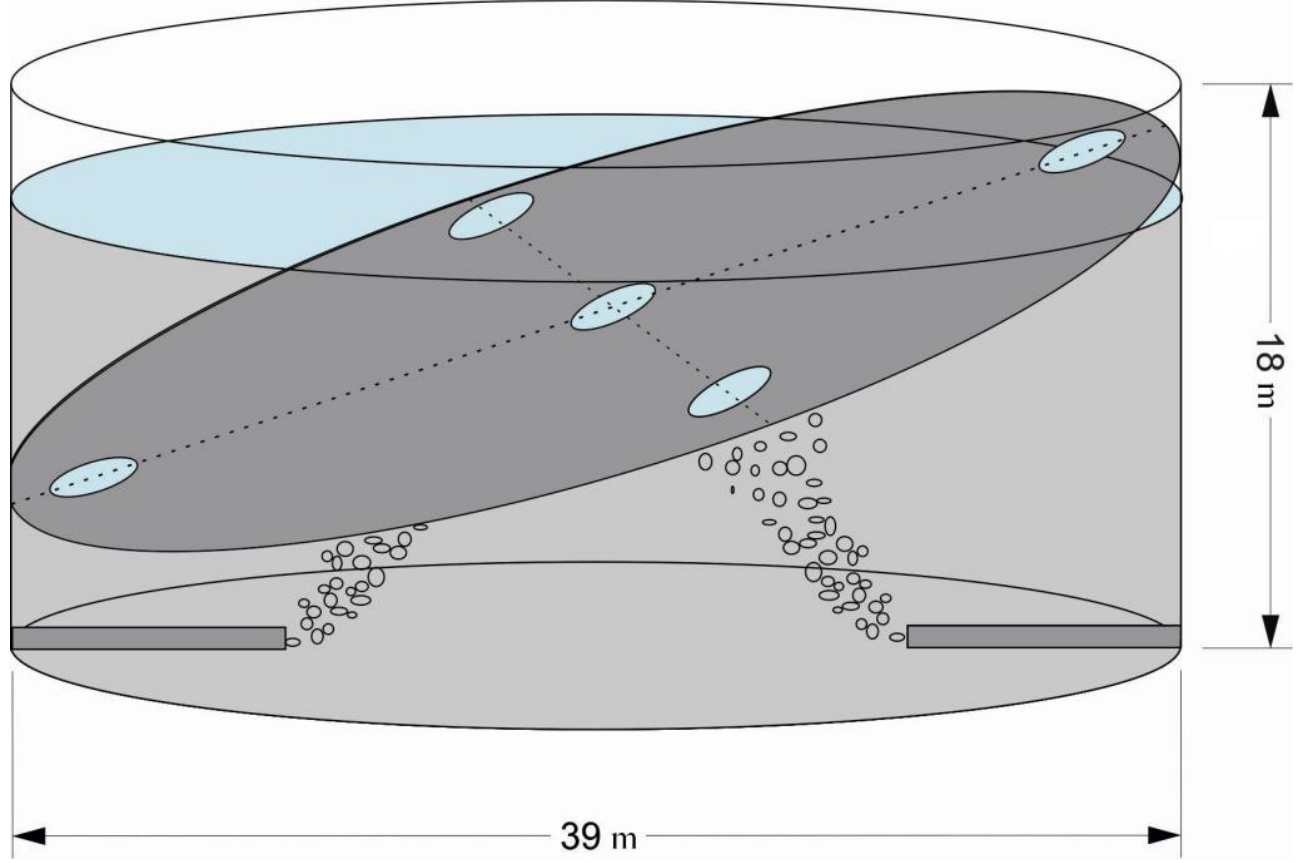

Fig. 1 - Inclination diagram of semi-flooded pontoon in RVSP-20000 tank 

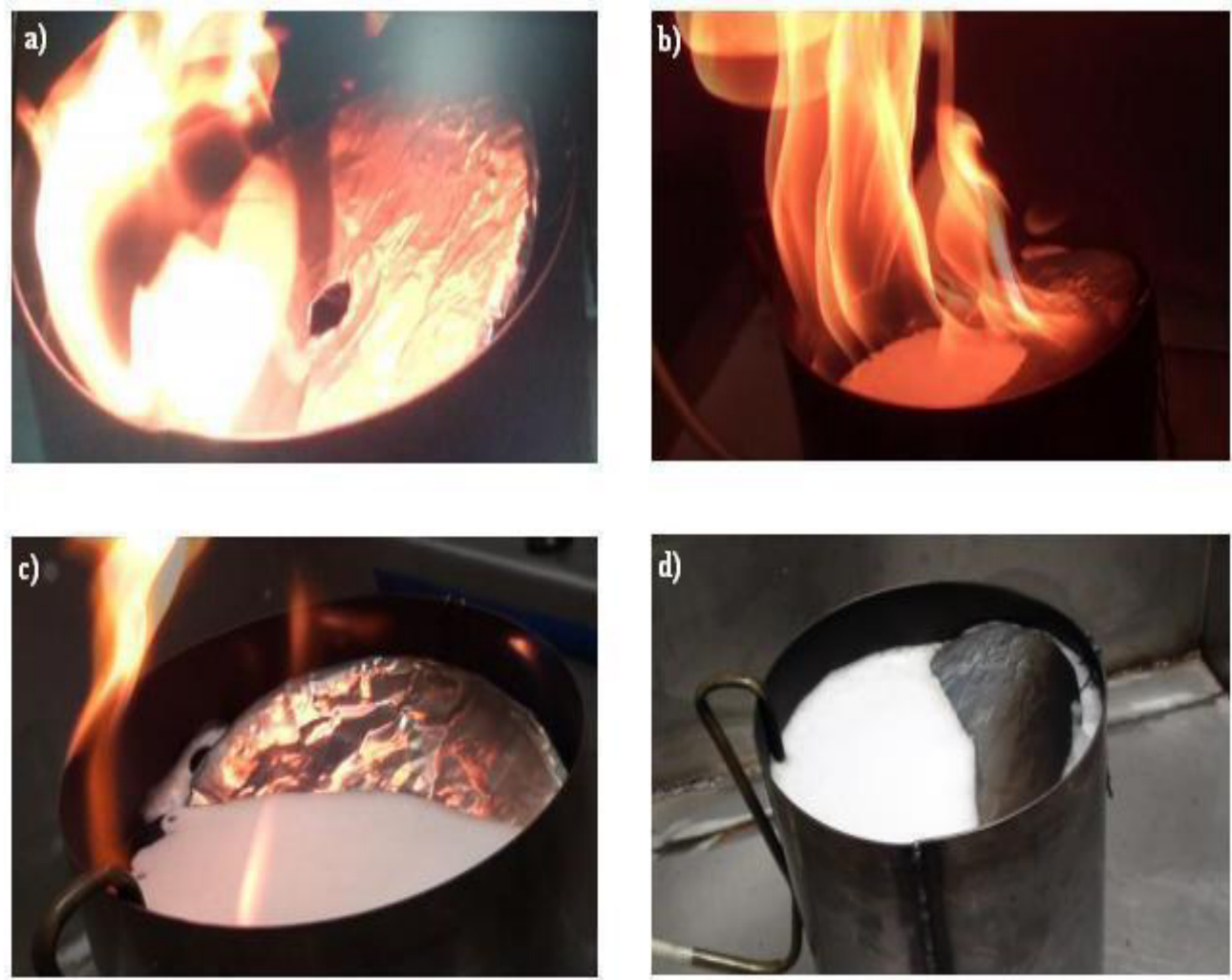

Fig.2. Images of heptane flames being extinguished in a pontoon tank model, with a central passage for foam to the open hydrocarbon area: a) Foam is supplied from the tank's bottom; b) Foam flows over to the second half; c) Flame is localized by the protective layer of foam; d) Flame is extinguished in both halves of the tank

We measured the time it took to put out heptane flames with the pontoon flooded to different degrees:

- the centrally located embrasure above the heptane layer;

- the centrally located embrasure semi-submerged in heptane layer;

- the centrally located embrasure fully submerged in heptane layer

In addition, we measured the time it took to extinguish the flames with embrasures of different sizes. The test used the bench design described in GOST R 53280.2-2010 for foaming agents made to extinguish flames of petroleum products burning inside tanks [9].

\section{Results and Discussion}

Extinguishing efficiency in the subsurface supply system in the presence of a pontoon can be boosted by changing the configuration of the pontoon or floating roof. Foam supplied from the tank's base is redistributed through embrasures provided regularly over the pontoon in a tank with diameter more than $25 \mathrm{~m}$ (Fig. 1). If the surface area is less, an embrasure is organized in the middle of the pontoon $[17,18]$.

The results of comparative extinguishing efficiency tests on the proposed design and prototype structure are shown in Table 1. Extinguishing efficiency is measured in units of time it takes to put out the flame at the constant rate of foam supply. 
Table 1. Results of comparative extinguishing efficiency tests on proposed design and prototype structure for semi-flooded pontoon

\begin{tabular}{|c|c|c|c|c|}
\hline $\begin{array}{c}\text { Foam supply rate, } \\
\mathrm{kg} /\left(\mathrm{m}^{2} \cdot \mathrm{sec}\right)\end{array}$ & $\begin{array}{c}\text { Flooding of central } \\
\text { pontoon embrasure }\end{array}$ & $\begin{array}{c}\text { Extinguishing time } \\
\text { using method/ } \\
\text { prototype, sec }\end{array}$ & $\begin{array}{c}\text { Extinguishing } \\
\text { time using } \\
\text { method, sec }\end{array}$ & $\begin{array}{c}\text { Relative } \\
\text { efficiency }\end{array}$ \\
\hline 0.08 & Embrasure above & $>150$ & 55 & 2.7 \\
0.10 & heptane level & $>150$ & 45 & 3.3 \\
\hline 0.08 & Embrasure half & $>150$ & 65 & 2.3 \\
0.10 & flooded & $>150$ & 55 & 2.7 \\
\hline 0.08 & Embrasure fully & $>150$ & 75 & 2.0 \\
0.10 & flooded & $>150$ & 65 & 2.3 \\
\hline
\end{tabular}

Experiments done on the model tank (Fig. 2) have demonstrated that foam cannot migrate over the pontoon's flooded part to the open surface of fuel. Foam is accumulated in half of the tank, while combustion in the tank's other half continues. The layer of foam from under a tilted pontoon reached the tank's upper edge but failed to spill over to the open surface. Therefore, no localization occurred, let alone total extinguishing of the flames. With embrasures, the flame can be extinguished by foam flowing through the open embrasure from the closed area to the tank's other half.

To solve the second problem, we propose using a water cooling system with water circulated through the girth that contains the filler. Surplus water spills down over drain tubes in the upper section of the girth. See Fig. 3 for a diagram of the circulating cooling system.

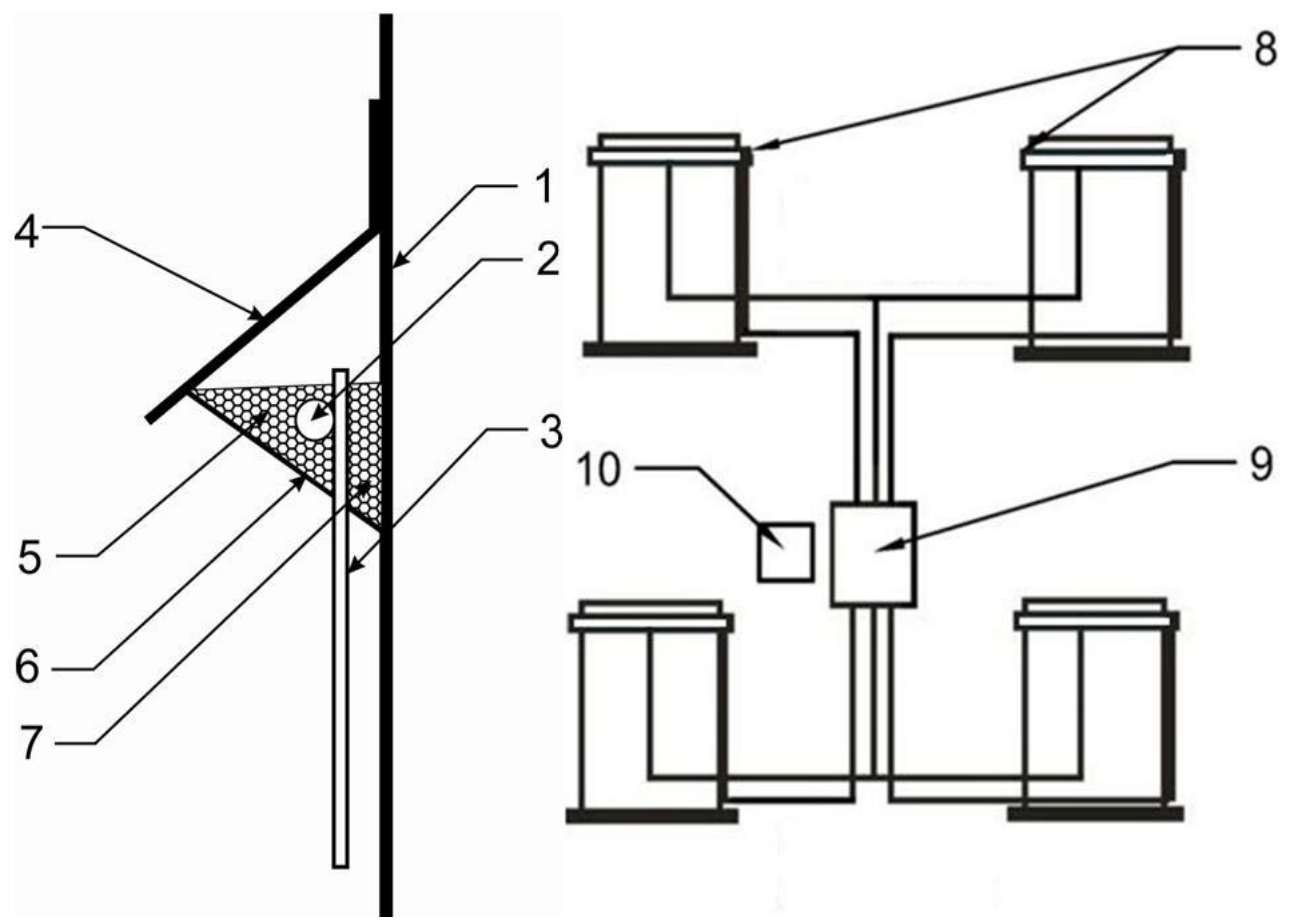

Fig.3. Circulation cooling system diagram: 1 - tank wall; 2 - perforated pipeline; 3 - overflow branch; 4 - protection plate; 5 -non-flammable porous filling agent; 6,8 - annular recess; 7 - porous system's surface layer adjoining the tank wall; 9 - pump; 10 - external expansion tank 
The tank is cooled with water solution of wetting agent, which is circulated by a pump between the annual recess on the tank wall and the external expansion tank. From the perforated pipeline, the water solution of wetting agent is injected into the porous noncombustible filling agent directly adjoining the tank wall, while surplus of the water solution in the annular recess returns into the circulation system by the overflow branches. To ensure sufficient efficiency, the level of solution in the annular recess should be above that of the porous filling agent.

Porous filling agent is a product of fiberglass or combustible heat insulation with through pores that prevent evaporation of water and keep feeding the surface layer of the porous system contacting with the tank wall, which cools the metal surface by absorbing heat as the wetting agent solution evaporates. As a result, the metal surface is not heated above the water boiling point; this prevents dangerous overheating of the combustible liquid inside the tank.

In term so the time needed to extinguish heptane flames, efficiency of the proposed cooling system is twice that of the existing one. If the device is used as proposed, the quantity of heat generated by a torch flame is halved compared to the prototype method. Direct records of the heat flow also demonstrated high efficiency of the proposed method that proved 1.5 times more efficient (Table 2).

Table 2. Comparative efficiency of methods by quantity of heat

\begin{tabular}{|c|c|c|c|c|}
\hline \multirow{2}{*}{$\begin{array}{c}\text { Burning time, } \\
\text { sec }\end{array}$} & Free board, cm & \multicolumn{2}{|c|}{ Quantity of heat, KJ } & \multirow{2}{*}{ Efficiency } \\
\cline { 3 - 4 } & & Prototype method & Proposed method & \\
\hline 30 & 5 & 3.7 & 2.1 & 1.9 \\
\hline 60 & 5 & 5.9 & 4.1 & 1.4 \\
\hline 120 & 5 & 11.2 & 7.1 & 1.6 \\
\hline
\end{tabular}

\section{Conclusions}

According to the research and resulting experimental data, the authors have proposed methods to improve fire protection of tanks with a pontoon or floating roof with subsurface supply of foam into the tank; the problem is solved by changing the configuration of said pontoons or floating roofs, and by using a cooling system for the nearby tanks. The results of science research have been practically implemented through patent coverage $[11,12]$.

\section{References}

1. V.A. Markeev, S.S. Voevoda, D.A. Korolchenko, Oil Industry 9, 83-85 (2006)

2. D.Korolchenko, S. Voevoda, MATEC Web of Conferences, 86, (2016)

3. A.F. Sharovarnikov, D.A. Korol'chenko D.A., Applied Mechanics and Materials, 475476, 1344-1350 (2014)

4. D.A. Korolchenko,A.F. Sharovarnikov, Fire and Explosion Safety, 23, 12, 59-68 (2014)

5. A.F. Sharovarnikov, G.I. Punchik, Colloid Journal, 44, 1, 180-182 (1982)

6. J.J. Bikerman, Foams. - New York: Springer (1973)

7. Oil Tank Fire Extinguishing // Fire. - October, (1960)

8. C. Jho, Journal of Colloid and Interface Science, 117, 1, 139-148 (1987)

9. D.A. Korolchenko, E.N. Degaev, A.F. Sharovarnikov, Determination of the Effectiveness of Extinguishing Foaming Agents in the Laboratory 2015 2nd 
International conference on material engineering and application, C 17-22 (ICMEA 2015)

10. D.A. Korolchenko, E.N. Degaev, A.F. Sharovarnikov, Dependence of Fire Extinguishing Efficacy of Low Expansion Foams Solutions Homology Sodium Sulfate on the Molecular Weight of the Surface-active Substances 2015 2nd International conference on material engineering and application (ICMEA 2015)

11. Yu. N, Shebeko, S.G. Tsariichenko, A. Ya. Korolchenko, A.N.Erofeev, Characteristics of combustion of hydrogen - methane - air mixtures in a closed vessel. Fizika Goreniya i Vzryva, 6, 52-56 (1991)

12. Yu. N, Shebeko, S.G. Tsariichenko, A. Ya. Korolchenko, A.N.Erofeev, Characteristics of combustion of hydrogen - methane - air mixtures in a closed vessel. Fizika Goreniya i Vzryva, 6, 52-56 (1991)

13. Zu. N. Shebeko, A. Ya. Korolchenko, E.D. Zamishevski, A.V. Trunev, Combustion and Flame, 117 (1-2), 438-440 (1999)

14. Xu. Lang - Procedia Engineering, 11, 189-195 (2011)

15. Q. Zhang, L.Wang, Y. Bi, (...), H. Zhi, P. Qiu, Journal of Hazardous Materials, 287, 7$92(2015)$

16. H. Ranjbar, B.H. Shahraki, Chemical Engineering and Technology, 36,2, 295-299 (2013)

17. Patent 2579730. Russian Federation, A62C3/06. Method to Extinguish Fire Emergencies of Petroleum and Products in Tanks with Pontoons or Floating Roof, by Supplying Foam to Tank Base / D.A. Korolchenko, A.F. Sharovarnikov, E.N. Degayev; Applicant and Patent Holder FGBOU VPO MGSU - № 2015101161/12; filed 16.01.2015; published 10.04.2016, Bulletin No. 10 - 9 pages.

18. Patent 2589613. Russian Federation, A62C3/00. Method to Extinguish Fire Emergencies of Petroleum and Products by Preventing Tank Overheating by Torch Flame / D.A. Korolchenko, A.F. Sharovarnikov, E.N. Degayev; Applicant and Patent Holder FGBOU VPO MGSU - № 2015101162/12; filed 16.01.2015; published 10.07.2016, Bulletin No. 9 - 7 pages. 